\title{
Valores hematológicos e bioquímicos de morcegos hematófagos (Desmodus rotundus rotundus) no sul do Brasil
}

\author{
Haematological and clinical biochemistry findings in hematophagous \\ bats (Desmodus rotundus rotundus) in southern Brazil
}

\begin{abstract}
Andrea Pires dos Santos ${ }^{1}$, Vanessa Daniele Mottin ${ }^{1}$, Rafael Sbicigo Aita ${ }^{2}$, Carine Franciscatto ${ }^{3}$, Sonia Terezinha dos Anjos Lopes ${ }^{4}$, Waylton dos Santos Franco ${ }^{5}$ \& Geder Paulo Hermann ${ }^{6}$
\end{abstract}

\begin{abstract}
RESUMO
Pertencentes à Família Desmodontidae da Classe Chiroptera, os morcegos hematófagos Desmodus rotundus rotundus são encontrados desde o México até a América do Sul, e se alimentam do sangue de outros animais. O objetivo deste trabalho foi estabelecer valores de referência para hemograma, proteínas plasmáticas totais (PPT), proteínas totais, albumina, globulinas, uréia e creatinina do morcego hematófago. Foram utilizados 65 animais, machos e fêmeas, capturados com redes especiais, em três localidades diferentes do Rio Grande do Sul. As amostras de sangue foram coletadas por punção intracardíaca e condicionadas em tubos contendo EDTA $\mathrm{K}_{2}$ e sem anticoagulante. A média e desvio padrão para contagem de eritrócitos (milhões/ $\mu \mathrm{L}$ ) foram respectivamente 8,56 e 0,68, para hemoglobina (g\%) 17,63 e 1,52 e para hematócrito (\%), 50,82 e 4,18. Para proteínas plasmáticas totais $(\mathrm{g} / \mathrm{dL})$ a média e desvio padrão foram respectivamente 7,75 e 0,39 . A contagem total de leucócitos $(/ \mu \mathrm{L})$ teve como média, 8412,5 e desvio padrão, 3135,7. Na contagem diferencial (\%) observou-se (média/desvio padrão) neutrófilos segmentados, neutrófilos não segmentados, linfócitos, monócitos e eosinófilos respectivamente $(84,5 / 7,73),(0,71 / 0,95),(11,29 / 7,48)$, $(3 / 1,39)$ e $(0,75 / 1,39)$. Não foram encontrados basófilos. Os valores de proteína total $(\mathrm{g} / \mathrm{L})$, albumina $(\mathrm{g} / \mathrm{L})$, globulinas $(\mathrm{g} / \mathrm{L})$, uréia $(\mathrm{mg} / \mathrm{dL})$ e creatinina $(\mathrm{mg} / \mathrm{dL})$ foram respectivamente (média/desvio padrão), $(75,1 / 15,4),(31 / 5,51),(44,43 / 10,85),(183,71 /$ $23,78)$ e $(0,81 / 0,22)$. Os presentes resultados poderão servir como valores de referência para o morcego Desmodus rotundus rotundus em futuras pesquisas.
\end{abstract}

Descritores: morcego, hematologia, bioquímica clínica, valor de referência.

\section{ABSTRACT}

Desmodus rotundus rotundus (Family Desmodontidae; Class Chiroptera) bats are found from Mexico to South America, mainly in carstic areas. The purpose of this study is to describe haematological and blood biochemistry findings of hematophagous bats (Desmodus rotundus rotundus) in order to establish reference values for this specie. Measurements were performed on blood from 65 wild bats captured in the southern Brazil. Complete blood count, total plasmatic proteins (plasma), total protein (serum), albumin, globulins, urea and creatinina were performed. Blood samples were obtained from intracardiac punction and collected into ethylene-diamine-tetraacetic-acid (EDTA) tubes and tubes without anticoagulant. These samples were used for hematology and clinical biochemistry, respectively. The erythrocyte count (millions/ $\mu \mathrm{L})$, hemoglobin ( $\mathrm{g} \%$ ) and packet cell volume $(\%)$ values (mean/standard deviation) were respectively $(8,56 / 0,68),(17,63 / 1,52)$ and $(50,82 / 4,18)$. Total plasma proteins $(\mathrm{g} / \mathrm{dL})$ values were $7,75 / 0,39$. The number of leukocytes $(/ \mu \mathrm{L})$ were (mean/standard deviation) $8412,5 / 3135,7$ and the differential count (\%) from neutrophils, band cells, lymphocytes, monocytes and eosinophils were respectively $(84,5 / 7,73),(0,71 / 0,95)$, $(11,29 / 7,48),(3 / 1,39)$ e $(0,75 / 1,39)$. No basophils were found. The values of total protein $(\mathrm{g} / \mathrm{L})$, albumin $(\mathrm{g} / \mathrm{L})$, globulins $(\mathrm{g} / \mathrm{L})$, urea $(\mathrm{mg} / \mathrm{dL})$ and creatinine $(\mathrm{mg} / \mathrm{dL})$ were respectively (mean/standard deviation), $(75,1 / 15,4),(31 / 5,51),(44,43 / 10,85)$, $(183,71 / 23,78)$ e $(0,81 / 0,22)$. Haematological and clinical biochemistry values given in this study can serve as reference values for hematophagous bats in southern Brazil.

Keywords: bat, hematology, clinical biochemistry, reference values. 


\section{INTRODUÇÃO}

Pertencentes à Família Desmodontidae da Classe Chiroptera, os morcegos hematófagos Desmodus rotundus rotundus são encontrados desde o México até a América do Sul, vivendo principalmente em regiões cársticas. Eles se alimentam do sangue de outros animais, e por essa razão é o principal vetor da raiva em herbívoros, doença que gera grandes prejuízos a pecuária nacional e que também pode afetar outros animais domésticos e o homem [1,11]. Pelo fato do morcego hematófago necessitar de outro animal para se alimentar ele voa longas distâncias e tende a se alimentar em grandes quantidades o que o tornaria muito pesado para voar novamente. Mecanismos adaptativos para essa espécie produzem uma urina diluída consistindo em grandes quantidades de água e pouca de solutos, porém a alimentação exclusivamente de sangue confere um elevado consumo de proteínas podendo gerar um excesso de uréia [6].

Devido às particularidades desta espécie e seus mecanismos adaptativos é necessário que valores de referência para esta sejam estabelecidos. Este trabalho teve como objetivo explorar hematologicamente e estabelecer valores normais de referência para hemograma, proteínas plasmáticas totais (PPT), uréia, creatinina, proteínas totais, albumina e globulinas do morcego hematófago, visto que este trabalho é inédito nesta espécie e poderá ser útil para novas pesquisas.

\section{MATERIAL E MÉTODOS}

Animais: foram utilizados para este trabalho 65 morcegos, machos e fêmeas, capturados com redes especiais em três localidades diferentes do estado do Rio Grande do Sul, Brasil (São Gabriel, São Martinho da Serra e São Pedro do Sul) [2].

Colheita e acondicionamento das amostras: As amostras de sangue foram coletadas por punção intracardíaca e condicionadas em tubos contendo EDTA $\mathrm{K}_{2}$ (etileno-diamino-tetra-acetato de potássio) a $10 \%$ na dosagem de uma gota para 2,5mL de sangue para realização do hemograma e proteínas plasmáticas totais $(n=34)$. Para as análises bioquímicas $(n=31)$ foram utilizados tubos sem anticoagulante onde os soros foram separados por centrifugação e congelados a $-20^{\circ} \mathrm{C}$ até a data das análises.

Análises hematológicas: Para o eritrograma ( $\mathrm{n}=34)$, o número de eritrócitos por microlitro de sangue foi obtido através da contagem manual na câmara de Neubauer. A dosagem de hemoglobina foi realizada atra- vés de hemoglobinômetro, pelo método da cianometahemoglobina que consiste na conversão de hemoglobina em cianometahemoglobina com adição de ferrocianeto de potássio e cianeto de potássio e leitura por espectrofotometria e o hematócrito ou volume globular (VG) foi obtido pela técnica do microhematócrito onde se utiliza tubo capilar preenchido com sangue, obliterado em uma extremidade e submetido à centrifugação a $15.000 \mathrm{rpm}$ por 5 minutos.

Os valores de Volume Corpuscular Médio (VCM) e Concentração de Hemoglobina Corpuscular Média (CHCM) foram obtidos através de cálculos [3]. O VCM, que corresponde ao volume médio dos eritrócitos e é expresso em fentolitros (fL) através da divisão do hematócrito multiplicado por dez pelo valor de eritrócitos. O CHCM corresponde à concentração média de hemoglobina dentro do eritrócito, é expresso em porcentagem e pode ser obtido pela divisão da hemoglobina multiplicada por cem pelo hematócrito.

Para o leucograma $(n=24)$, a contagem total de leucócitos que é expressa em células por microlitros $(\mu \mathrm{L})$ e foi obtida através da câmara de Neubauer e o diferencial leucocitário foi realizado por microscopia através do esfregaço sanguiíneo corado pelo método de Giemsa [9].

O valor das proteínas plasmáticas totais (PPT) foi obtido no plasma por refratometria.

Análises bioquímicas: As proteínas totais $(n=26)$ e albumina $(n=28)$ foram mensuradas no soro através dos métodos de biureto e verde de bromocresol, respectivamente, utilizando-se espectofotometria. As globulinas $(n=26)$ foram estimadas pela diferença da concentração de proteínas totais e albumina. A uréia $(n=28)$ pelo método enzimático de Berthelot e a creatinina $(n=27)$ pelo método do picrato, de acordo com as instruções dos fabricantes.

Os resultados foram comparados com os valores de referência descritos na literatura para cão, gato, primatas não humanos, equinos, bovinos, ovinos e suínos.

\section{RESULTADOS}

Os valores do eritrograma, contagem total de leucócitos e diferencial leucocitário dos morcegos estão apresentados nas Tabelas 1 e 2 e os valores de bioquímicos na Tabela 3 .

Foi observada a presença de policromasia e anisocitose leve em $82 \%$ das amostras, presença de corpúsculos de Howell Jolly em $64 \%$ e metarrubrícitos 
Tabela 1. Valores do eritrograma de morcegos hematófagos (Desmodus rotundus rotundus) no sul do Brasil.

\begin{tabular}{lc}
\hline \multicolumn{1}{c}{ Variável } \\
\hline VG \% \\
Média $\pm d p$ \\
$\quad$ Intervalo \\
Hemoglobina (g/dL) \\
$\quad$ Média $\pm d p$ \\
$\quad$ Intervalo \\
Eritrócitos/ $\boldsymbol{\mu L}$ \\
$\quad$ Média $\pm d p$ \\
$\quad$ Intervalo \\
VCM (fL) \\
$\quad$ Média $\pm d p$ \\
Intervalo \\
CHCM (\%) \\
$\quad$ Média $\pm d p$ \\
Intervalo
\end{tabular}

de 1 a 5/100 leucócitos em 47\%. Para proteínas plasmáticas totais $(\mathrm{g} / \mathrm{dL})$ a média e desvio padrão foram respectivamente 7,76 e 0,40 . Não foram observados basófilos em nenhuma amostra.

\section{DISCUSSÃO}

Hematologia: Os valores para o eritrograma são semelhantes à maioria das espécies mamíferas com valores de referência conhecidos [4,5,9]. Para o leucograma, observou-se uma alta predominância de neutrófilos sobre linfócitos e ausência de basófilos. O número de linfócitos é baixo em relação à maioria das espécies mamíferas e pode estar relacionado com o estresse dos animais mediante a captura. A resposta ao estresse pode ser detectada por mudanças no leucograma sendo a mudança mais importante a linfopenia. Os corticóides liberados no estresse induzem a apoptose e a recirculação dos linfócitos. A segunda mudança mais expressiva é a neutrofilia onde os esteróides diminuem a marginalização e a diapedese dos neutrófilos retendo-os

Tabela 2. Valores do leucograma de morcegos hematófagos (Desmodus rotundus rotundus) no sul do Brasil.

\begin{tabular}{|c|c|c|}
\hline Variável & Valores relativos (\%) & Valores absolutos $(/ \mu \mathrm{L})$ \\
\hline \multicolumn{3}{|l|}{ Leucócitos } \\
\hline Média $\pm d p$ & & $8412,5 \pm 3135,67$ \\
\hline Intervalo & & $2700-14100$ \\
\hline \multicolumn{3}{|l|}{ Bastonetes } \\
\hline Média \pm dp & $0,71 \pm 0,95$ & $62,04 \pm 93,75$ \\
\hline Intervalo & $0-3$ & $0-360$ \\
\hline \multicolumn{3}{|l|}{ Neutrófilos } \\
\hline Média $\pm d p$ & $84,71 \pm 7,36$ & $7068,04 \pm 2525,11$ \\
\hline Intervalo & $64-94$ & $2376-11094$ \\
\hline \multicolumn{3}{|l|}{ Linfócitos } \\
\hline Média \pm dp & $11,17 \pm 7,16$ & $985,25 \pm 880,31$ \\
\hline Intervalo & $3-31$ & $160-4371$ \\
\hline \multicolumn{3}{|l|}{ Monócitos } \\
\hline Média $\pm d p$ & $3 \pm 2,4$ & $244,63 \pm 215,29$ \\
\hline Intervalo & $0-10$ & $0-774$ \\
\hline \multicolumn{3}{|l|}{ Eosinófilos } \\
\hline Média \pm dp & $0,75 \pm 1,39$ & $68,54 \pm 144,27$ \\
\hline Intervalo & $0-6$ & $0-654$ \\
\hline \multicolumn{3}{|l|}{ Basófilos } \\
\hline Média \pm dp & 0 & 0 \\
\hline Intervalo & 0 & 0 \\
\hline
\end{tabular}


Tabela 3. Valores de proteínas totais, albumina, globulinas, uréia e creatinina de morcegos hematófagos (Desmodus rotundus rotundus) no sul do Brasil.

\section{Variável}

\section{Proteínas totais $(\mathrm{g} / \mathrm{L})$}

Média $\pm d p$

$75,1 \pm 15,4$

Intervalo

$43-104$

Albumina ( $g / L)$

Média $\pm \mathrm{dp}$

$31 \pm 5,51$

Intervalo

$18,2-42,7$

Globulinas (g/L)

Média \pm dp

$44,43 \pm 10,85$

Intervalo

$24,8-63,4$

Uréia $(\mathrm{mg} / \mathrm{dL})$

Média \pm dp

$183,71 \pm 23,78$

Intervalo

$130-231$

Creatinina $(\mathrm{mg} / \mathrm{dL})$

Média $\pm d p$

$0,81 \pm 0,22$

Intervalo

$0,5-1,3$ na circulação [10] logo, o número elevado de neutrófilos também pode estar relacionado ao estresse. A eosinopenia é considerada a terceira mudança que pode ocorrer no leucograma de estresse podendo significar que os eosinófilos dos animais em estudo podem estar um pouco diminuídos em relação ao seu valor normal. Os valores de PPT também são semelhantes as demais espécies comparadas.

Bioquímica clínica: Os valores para creatinina, proteínas totais, albumina e globulinas foram semelhantes à maioria das espécies mamíferas conhecidas [4,5]. Os valores de uréia apresentam-se maiores do que os valores de referência das demais espécies verificadas. Estudos da função renal do morcego hematófago revelaram valores de uréia entre 75,6 e 159,6 mg/dL também maiores do que as demais espécies [6]. A uréia é sintetizada nos hepatócitos proveniente do metabolismo das proteínas [8]. O valor elevado no morcego hematófago pode estar relacionado à dieta excessivamente protéica por se tratar exclusivamente do sangue de outros animais.

\section{CONCLUSÃO}

Os resultados deste estudo podem servir como valores de referência para futuras pesquisas em morcegos hematófagos Desmodus rotundus rotundus.

\section{REFERÊNCIAS}

1 Eisenberg J.F. \& Redford K.H. 1999. Mammals of the neotropics. The central neotropics: Ecuador, Peru, Bolivia, Brazil. $3^{\text {rd }}$ edn. Chicago: University of Chicago, 610p.

2 Flores Crespo R., Velarde F.I. \& López D.A. 1976. Vampirinip II. Un producto utilizable en tres metodos para el combate del murcielago hematófago. Técnica Pecuária México.30:67-75.

3 Jain N.C. 1986. Schalm's Veterinary Hematology. $1^{\text {st }}$ edn. Philadelphia: Lea and Febiger, 1221p.

4 Jain N.C. 1993. Essentials of Veterinary Hematology. $1^{\text {st }}$ edn. Philadelphia: Lea and Febiger, 417p.

5 Kaneko J.J., Harvey J.W. \& Bruss M.L. 1997. Clinical Biochemestry of domestic animals. 5th edn. New York: Academic Press, 932p.

6 McFarland W.N. \& Wimsatt W.A. 1969. Renal function and its relation to the ecology of the vampire bat, Desmodus rotundus. Comparative Biochemistry and Physiology 28: 985-1006.

7 Mayen F. 2003. Haematophagous bats in Brazil, their role in rabies transmission, impact on public health, livestock industry and alternatives to an indiscriminate reduction of bat population. Journal of Veterinary Medicine Series B, 50: 469-472.

8 Morris S.M.Jr. 1992. Reagulation of enzymes of urea and arginine biosyntesis. Annual Review of Nutition, 12:81-101.

9 Schalm O.W., Jain N.C. \& Carrol E.J. 1975. Veterinary Hematology. 3rd edn. Philadelphia: Lea and Febiger, 807 p.

10 Thrall M.A. 2004. Veterinary Hematology and Clinical Chemistry. ${ }^{\text {st }}$ edn. Philadelphia: Lippincott Williams \& Wilkins, 518p.

11 Uieda W. 1995. The common vampire bat in urban environments from Southeastern Brazil. Chiroptera Neotropical. 1: 22-24.

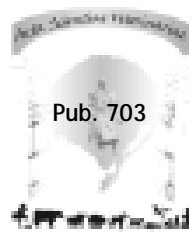

